\title{
Placas cimentícias e pavers com incorporação de rejeitos da coleta seletiva do município de Blumenau, SC
}

\author{
Cement plates and pavers made with waste from the \\ sorting process in Blumenau, SC, Brazil
}

\section{J oão Marcos Bosi Mendonça de Moura Rafael Reis \\ Samantha May Ivone Gohr Pinheiro}

\section{Resumo}

A nalisou-se o desempenho físico-mecânico de placas e pavers com incorporação de rejeitos da coleta seletiva do município de Blumenau, SC. Tais rejeitos são compostos de orgânicos, polímeros, papéis, vidro e têxteis, que foram reduzidos de tamanho (2,4 $\mathrm{mm}$ a $19,0 \mathrm{~mm})$ e substituíram o agregado miúdo natural nos percentuais de 5\%, 10\%, 20\% e 30\%. Para o compósito no estado fresco verificou-se o índice de consistência, e no estado endurecido determinaram-se massa específica aparente, absorção de água e resistência à compressão. As placas foram submetidas ao ensaio de resistência à flexão e à análise de microscopia eletrônica de varredura. A massa específica aparente das placas variou de 0,8 a 1,6 g.cm ${ }^{-3}$, e dos pavers, de 1,78 a 1,84 g.cm ${ }^{-3}$. Para menores quantidades de rejeitos incorporados, os dois materiais apresentaram índices de absorção de água que satisfazem as exigências de normas correlatas. As placas apresentaram valores de resistência à compressão que variaram de 4,7 MPa a 14,6 MPa. Na flexão, os valores atingidos foram de 0,1 MPa a 1,8 MPa. Os pavers alcançaram valores de resistência à compressão entre 10,8 MPa e 18,7 MPa. Pavers com 5\% de incorporação de agregados de rejeitos seriam passíveis de ser aplicáveis em calçadas e meios-fios desde que estudos futuros garantam sua durabilidade.

J oão Marcos Bosi Mendonça de Fundação Universidade Roura gional de Blumenau Blumenau - SC - Brasil

Rafael Reis Fundação Universidade Regional de Blumenau Blumenau - SC - Brasil

Samantha May Fundação Universidade Regional de Blumenau - SC - Brasil

Ivone Gohr Pinheiro Fundação Universidade Regional de Blumenau Blumenau - SC - Brasil

Recebido em 23/02/16

Aceito em 13/03/17
Palavras-chave: Reciclagem. Rejeitos. Materiais da construção civil.

\section{Abstract}

This project analysed the physical-mechanical performance of plates and pavers with the incorporation of waste originated from the sorting process in the city of Blumenau, SC, Brazil. The waste consisted of organic waste, polymers, paper, glass and textile materials which were reduced in size (2.4 $\mathrm{mm}$ to $19.0 \mathrm{~mm}$ ) and then used to replace natural aggregate at different ratios: 5\%, 10\%, 20\% and $30 \%$. The consistence of the fresh mortar and the physical-mechanical indices, the apparent specific gravity, water absorption and compressive strength of the hardened mortar were determined. Scanning electron microscopy analysis and flexural strength tests were also conducted. The bulk density of the plates and pavers ranged from 0.8 to $1.6 \mathrm{~g} . \mathrm{cm}-3$ and 1.78 to $1.84 \mathrm{~g} . \mathrm{cm}-3$ respectively. In the case of low incorporation of waste, both materials presented water absorption results that meet the requirements of correlated standards. The plates presented compressive strength values ranging from 4.7 MPa to 14.6 MPa. Flexural strength results reached values between $0.1 \mathrm{MPa}$ and 1,8 $\mathrm{MPa}$. The pavers achieved compressive strength values between 10.8 MPa and 18.7 MPa. Pavers with 5\% incorporation of waste aggregates could be used in sidewalks and curbs, as long as future studies are able to demonstrate their durability.

Keywords: Recycling. Waste. Construction materials. 


\section{Introdução}

Os desafios na gestão dos resíduos sólidos, apesar de todos os avanços, ainda são presentes, e entre tantos, pode-se destacar a meta de ampliação da coleta seletiva e, consequentemente, o incentivo à reciclagem, reutilização e recuperação de resíduos sólidos urbanos (BRASIL, 2012). Contudo, essa ampliação nem sempre vem acompanhada de estruturas capazes de absorver os materiais potencialmente (re)aproveitáveis e de uma conscientização ambiental da população a respeito do que efetivamente se deve encaminhar à coleta seletiva.

Não raras vezes, essas situações geram uma significativa quantidade de rejeitos na coleta seletiva dos municípios brasileiros, ou seja, uma grande quantidade de resíduos que, depois de esgotadas todas as possibilidades de tratamento e recuperação, não apresentam outra possibilidade a não ser a disposição final (BRASIL, 2010). Moura (2016), por exemplo, observou que em Blumenau, Santa Catarina, a Associação de Trabalhadores de Materiais Recicláveis do município (Reciblu) rejeitou de dezembro de 2014 a novembro de 2015 aproximadamente $345 \mathrm{t}$.

Nesse contexto, alternativas tecnológicas que promovam a inserção dos rejeitos em uma cadeia produtiva podem mitigar o uso de recursos naturais e reduzir gastos públicos com a disposição final. Estudos reconhecem que a incorporação desses resíduos e rejeitos em materiais cimentícios pode reduzir custos e promover benefícios ambientais (SAIKIA; BRITO, 2014; TONET; GORNINSKI, 2013; FRIGIONE, 2010). Assim, o que se observa na literatura científica é uma significativa quantidade de estudos com concretos e incorporação de resíduos poliméricos.

Resíduos recicláveis (PET, PP, EPS, papéis e vidro) foram incorporados em placas cimentícias por Moura e Matos (2015). Nesse estudo, determinou-se a resistência à flexão para placas compostas pela relação 1:2, $1: 3$ e $1: 4$ (resíduo:argamassa), resultando em 1,0, 1,4 e 1,7 $\mathrm{MPa}$, respectivamente. Nos testes de resistência à compressão, os compósitos com resíduos recicláveis da coleta seletiva foram ensaiados através da aplicação da NBR 5739 (ABNT, 2007). O estudo identificou, para uma relação de 1:2, 1:3 e 1:4 (resíduos: argamassa), valores de 4,02, 3,55 e 4,36 $\mathrm{MPa}$ respectivamente. Ao compararem os índices de produtos já comercializados no mercado, os autores concluíram que as placas poderiam ser aplicadas em vedações verticais e horizontais (forros) de residências

Albano et al. (2009), ao estudarem o comportamento mecânico de concreto com polietileno tereftalato (PET) reciclado, utilizaram relações de água-cimento na faixa de 0,5 a 0,6. Os resultados indicaram uma relação entre o volume e o tamanho de partícula de PET com parâmetros físicos e mecânicos. Verificou-se que, na medida em que se aumentava a presença de PET, reduziase a trabalhabilidade do compósito, assim como se reduziam parâmetros mecânicos como a resistência à compressão, à tração, à flexão e o módulo de elasticidade. Em contrapartida, a absorção de água aumentava devido ao aumento da porosidade que o resíduo proporcionava.

De modo semelhante, Rahmani et al. (2013) estudaram os efeitos da substituição do agregado miúdo por PET reciclado. Propriedades do concreto fresco, assim como do concreto endurecido, foram avaliadas. Os resultados mostraram que o concreto fresco com partículas de PET apresenta menor trabalhabilidade e massa específica. Testes ultrassônicos revelaram uma estrutura relativamente mais porosa para o concreto contendo partículas de PET.

Essas partículas de PET podem prejudicar a aderência entre a pasta cimentícia e os agregados, provocando diminuição do desempenho mecânico dos compósitos (SHARMA; BANSAL, 2016). Ainda, segundo Sharma e Bansal (2016), a maioria dos estudos que trabalham com compósitos cimentícios observou que a adição de polímeros reduz a resistência à compressão. Alguns estudos relatam, no entanto, que a incorporação de polímeros em formato de fibra resultou no aumento da resistência à compressão quando adicionados em quantidades relativamente reduzidas (PRAHALLADA; PARKSH, 2013; RAMADEVI; MANJU, 2012; MALAGAVELI, 2011).

Ademais, destaca-se que a influência desses resíduos se dá em diferentes graus para diferentes esforços mecânicos. Por exemplo, observa-se nos estudos um impacto negativo maior na resistência à compressão do que na resistência à flexão quando se incorporam resíduos em substituição ao agregado miúdo natural (SAIKIA; BRITO, 2014; BATAYNEH; MARIE; ASI, 2007). Considerando esses aspectos, objetivou-se neste artigo avaliar o desempenho de dois materiais da construção civil com incorporação de rejeitos da coleta seletiva que possuem diferentes esforços mecânicos; o primeiro, as placas cimentícias, para as quais a resistência à flexão é um fator preponderante para seu adequado desempenho mecânico; e, o segundo, os pavers, cujos esforços compressivos são decisivos para sua viabilidade de uso. 


\section{Método}

O agregado miúdo natural utilizado nas placas cimentícias de vedação e nos pavers foi substituído por agregados de rejeitos provenientes da coleta seletiva de Blumenau, SC. Uma vez coletados, os agregados de rejeitos foram tratados (moídos) visando diminuir seu tamanho. A seguir, descrevese a caracterização dos agregados de rejeitos utilizados, traços e procedimentos de produção dos compósitos, e os ensaios físicos e mecânicos executados.

\section{Agregados de rejeitos}

Os rejeitos utilizados e resultantes do processo de segregação dos resíduos sólidos da coleta seletiva blumenauense foram orgânicos (alimentos, embalagens com predominância de líquido/material orgânico, material de higiene pessoal, papéis degradados e umedecidos), polímeros (embalagens), papéis, vidro (embalagens) e têxteis (camisas, calças jeans, roupa íntima, etc.). Essas categorias representam em média 78,3\% dos rejeitos da coleta seletiva de Blumenau, SC (MOURA, 2016).

As composições dos agregados de rejeitos encontram-se expressas na Tabela 1. Elas foram determinadas a partir do estudo de Moura (2016), que realizou oito análises, totalizando uma amostra de $400 \mathrm{~kg}$ de rejeitos no mês de janeiro de 2015 . Gerou-se a composição gravimétrica com 17 categorias, entre as quais 5 foram selecionadas para ser incorporadas aos materiais.

Três misturas de rejeitos foram aplicadas. A primeira composição (C1) abrangeu o máximo de categorias que se julgaram a priori viáveis de ser incorporadas: orgânicos, polímeros, papéis, vidro e têxteis, e foi denominada de C1. A composição 2 (C2) contemplou todas as classes da composição C1, porém sem a presença dos orgânicos, e a composição 3 (C3) continha somente os polímeros rejeitados da coleta seletiva. Os rejeitos utilizados estavam misturados aos demais e foram segregados na RECIBLU em meses diferentes (março, abril e maio de 2015).

Decidiu-se reduzir o volume do rejeito de vidro na máquina Los Angeles considerando os estudos de Moura e Matos (2015) e Oliveira, Brito e Veiga (2013). O processo de redução do tamanho deu-se com cargas abrasivas (12 esferas de aço) durante um período de $10 \mathrm{~min}$ a $45 \mathrm{~min}$ (dependendo da granulometria desejada da areia) e à rotação de 24 rpm. Uma vez transformado o rejeito de vidro em agregado de rejeito de vidro, este e a areia natural foram submetidos à determinação da distribuição granulométrica (Figura 1), que ficou dentro das faixas recomendadas pela NBR 7211 (ABNT, 2009) e ASTM C33 (AMERICAN..., 2003).

Os agregados de rejeitos não vítreos (aqueles classificados como "orgânicos", "polímeros", "papéis" e "têxteis”) foram triturados num moinho de facas. Obtiveram-se, deste modo, os rejeitos em formato de partículas de tamanho entre $2,4 \mathrm{~mm}$ e 19,0 mm (Figura 2). Os rejeitos não vítreos foram submetidos ao ensaio de massa unitária no estado solto determinado através da NBR NM 45 (ABNT, 2006a).

\section{Traços}

Na Tabela 2 é possível observar uma síntese da porcentagem de substituição do agregado miúdo natural (areia) por agregado de rejeito em cada material da construção civil trabalhado. A placa cimentícia com e sem agregado de rejeito incorporado foi executada na relação 1:1 (cimento:agregado) em massa.

Os pavers sem incorporação de agregado de rejeito foram fabricados na relação 1:3 e com incorporação na proporção de 1:1 (cimento:agregado) em massa. Utilizou-se o cimento do tipo CP V-ARI e o fator água/cimento de 0,5 em ambos os compósitos, tendo como referência os estudos de Albano et al. (2009) e Rahmani et al. (2013), que pesquisaram materiais cimentícios com incorporação de resíduos poliméricos.

Tabela 1 - Composição dos rejeitos incorporados nas placas e nos pavers

\begin{tabular}{l|c|c|c}
\hline \multicolumn{1}{c|}{ Tipos de rejeitos } & \multicolumn{2}{c}{ Composição dos rejeitos utilizados (\%) } \\
\cline { 2 - 4 } & C1 & C2 & C3 \\
\hline $\begin{array}{l}\text { Orgânicos: alimentos, embalagens com } \\
\text { predominância de líquido/material orgânico, material } \\
\text { de higiene pessoal, papéis degradados e umedecidos }\end{array}$ & 24 & $--\mathrm{X}--$ & - --X-- \\
\hline Polímeros: embalagens & 33 & 44 & 100 \\
\hline Papéis: branco, misto e papelão & 16 & 21 & $--\mathrm{X}--$ \\
\hline Vidro: embalagens & 24 & 31 & $--\mathrm{X}--$ \\
\hline Têxteis: camisas, calças jeans, roupa íntima, etc. & 3 & 4 & - --X-- \\
\hline
\end{tabular}


Figura 1 - Composição granulométrica do agregado miúdo natural e de rejeito de vidro

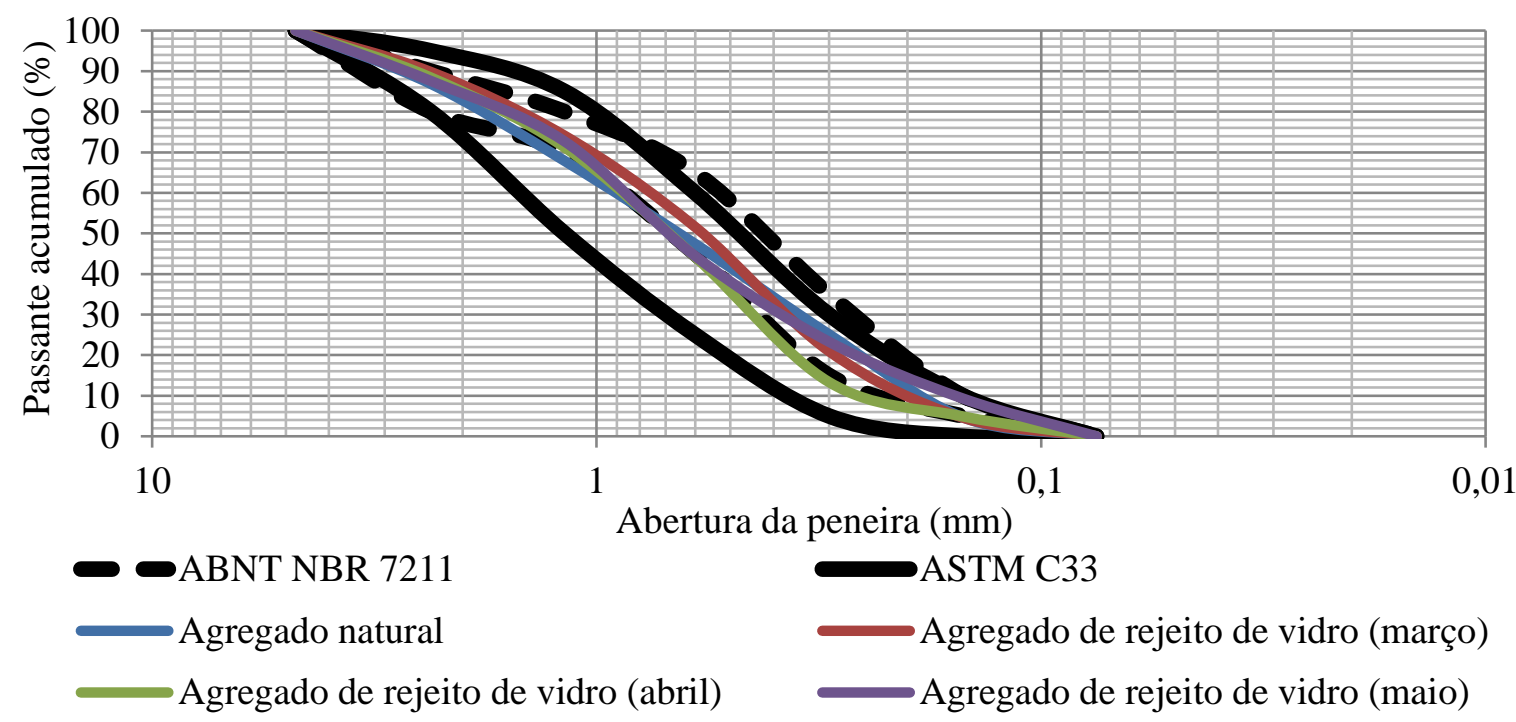

Figura 2 - Rejeito não vítreos após a trituração: C1 sem o vidro (orgânicos, polímeros, papéis e têxteis), C2 sem o vidro (polímeros, papéis e têxteis) e C3 (polímeros)

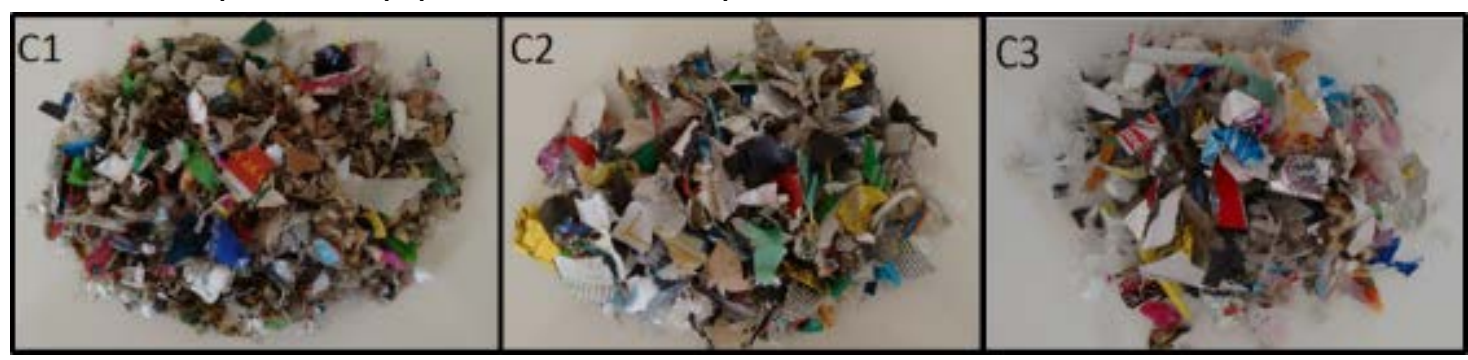

Tabela 2 - Síntese das porcentagens de incorporação de rejeitos nas placas cimentícias e nos pavers

\begin{tabular}{l|c|c}
\hline \multicolumn{1}{c|}{ Composição do rejeito } & \multicolumn{2}{|c}{$\begin{array}{c}\text { Placa cimentícia } \\
\text { Quantidade de agregado natural } \\
\text { substituído por agregado de rejeito (\%) }\end{array}$} \\
\hline Sem incorporação & 0 & 0 \\
\hline C1: Orgânicos, polímeros, & 5 & 5 \\
papéis, vidro e têxteis & 20 & 10 \\
\hline C2: Polímeros, papéis, & 30 & $--\mathrm{X}--$ \\
vidro e têxteis & 5 & 5 \\
& 20 & 10 \\
\multirow{2}{*}{ C3: Polímeros } & 30 & $--\mathrm{X}--$ \\
\hline
\end{tabular}

\section{Produção dos compósitos}

\section{Placas cimentícias}

As placas cimentícias e os corpos de prova cilíndricos foram preparados em um misturador mecânico. Para cada traço executaram-se placas com dimensões de 330x100x12,5 mm, conforme também trabalharam Moura e Matos (2015).
Utilizaram-se corpos de prova cilíndricos de diâmetro igual a $50 \mathrm{~mm}$ e altura de $100 \mathrm{~mm}$ (ABNT, 1997).

Ao todo foram confeccionadas 30 placas e corpos de prova cilíndricos para contemplar as três composições de rejeitos (C1, C2 e C3) e os percentuais de incorporação $(0 \%, 5 \%, 20 \%$ e $30 \%$ ). Os rejeitos utilizados para um mesmo traço

348 Moura, J. M. B. M. de; Reis, R.; May, S.; Pinheiro, I. G. 
foram coletados em meses diferentes, março, abril e maio de 2015, gerando um experimento em triplicata a fim de garantir a reprodutibilidade (Figura 3).

\section{Pavers}

A mistura dos componentes dos pavers foi feita primeiramente colocando-se o agregado miúdo natural, cimento e água de amassamento, sendo depois acrescentados os agregados de rejeitos, misturando-se a argamassa até que apresentasse homogeneidade. As peças foram executadas em uma única camada, com dimensões comerciais de 220x110x60 mm. O material de dosagem era colocado na forma de aço do equipamento, untada com uma camada fina de óleo vegetal, e em seguida comprimido. Após a prensagem (Figura 4), eram retirados da máquina e submetidos à cura seca, assim como as placas cimentícias.

\section{Ensaios}

No estado fresco determinou-se o índice de consistência das placas cimentícias (ABNT, 2005b).

No estado endurecido o ensaio de absorção de água por imersão na placa e no paver foi realizado com o emprego de três corpos de prova para cada uma das composições no $26^{\circ}$ e no $25^{\circ}$ dia de cura respectivamente. Adotaram-se os procedimentos conforme definido na norma NBR 9778 (ABNT, 2005a) com adaptação referente à temperatura no interior da estufa. Neste caso, reduziu-se a temperatura devido à presença dos rejeitos. Assim, as placas e os pavers foram submetidos a secagem em estufa a $70{ }^{\circ} \mathrm{C}$.

Nas placas determinou-se a absorção de água e executou-se o ensaio de resistência à flexão no estado saturado aos 28 dias de cura. Neste ensaio aplicou-se uma velocidade de deslocamento igual a $1,3 \mathrm{~mm} / \mathrm{min}$. Os pontos de apoio e de aplicação da carga encontram-se ilustrados na Figura 5, e o cálculo da resistência baseou-se nos procedimentos da ASMT (AMERICAN..., 1999).

Figura 3 - Molde metálico fracionado em três corpos de prova - placas

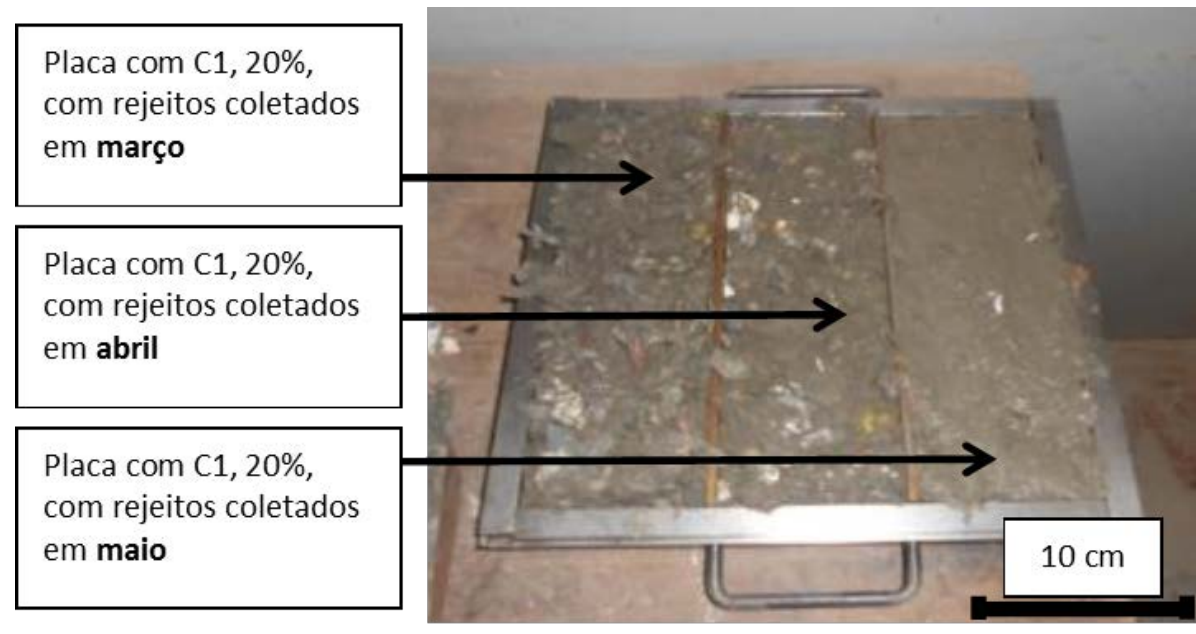

Figura 4 - Processo de fabricação do paver: (a) compósito após a mistura de todos os componentes; (b) compósito assentado (pré-moldagem); e (c) compósito já prensado e desmoldado (desmolde)

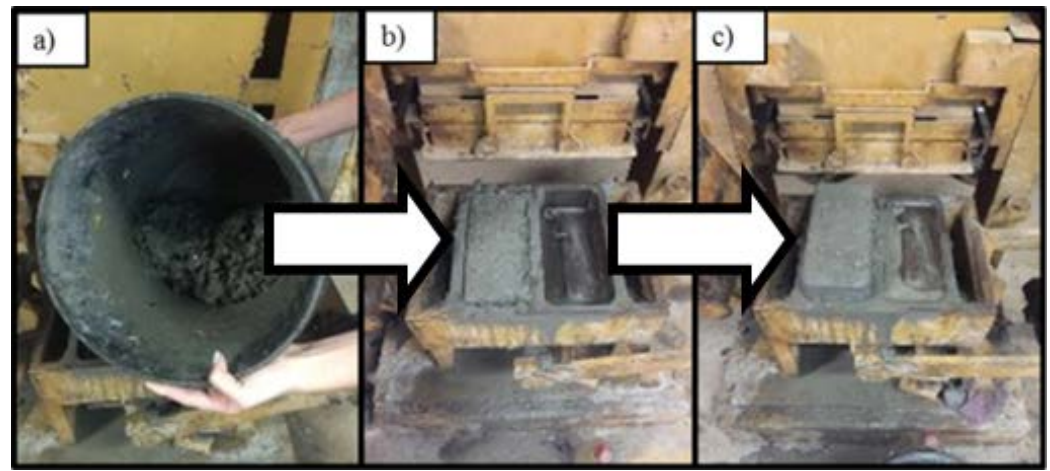


Figura 5 - Dimensões dos corpos de prova (placas) e ensaio de resistência à flexão

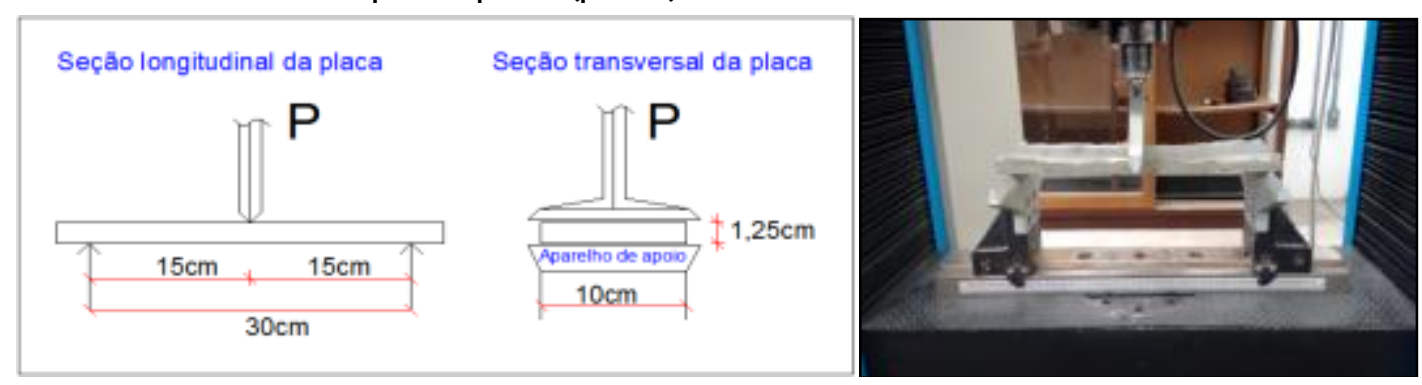

O ensaio de determinação da resistência à compressão simples para o compósito da placa foi realizado por meio de corpos de prova cilíndricos (ABNT, 1997). No caso dos pavers, após serem submetidos ao ensaio de absorção de água no $25^{\circ}$ dia e ser executado o capeamento em ambas as faces, os pavers foram testados à compressão no $28^{\circ}$ dia de cura (ABNT, 1997). Os resultados foram gerados a partir de três amostras para cada traço.

A massa específica aparente também foi determinada para cada corpo de prova em formato de placa e paver através da relação massa total no estado endurecido (antes de ser submetido ao ensaio de absorção de água por imersão) e seu volume total.

\section{Microscopia Eletrônica de Varredura - MEV}

Uma análise microestrutural foi realizada em amostras retiradas das placas cimentícias utilizando-se microscópio eletrônico de varredura da marca Tescan, modelo Vega 3 LMH/LMU. Objetivou-se verificar a porosidade do compósito e o arranjo dos rejeitos com a pasta cimentícia. As placas analisadas eram compostas de $5 \%$ de rejeito nas composições C1, C2 e C3 (coletados no mês de março). Os compósitos foram serrados e reduzidos a um volume aproximado de $1 \mathrm{~cm}^{3}$.

\section{Análises estatísticas}

Todos os resultados obtidos foram submetidos a tratamento estatístico, testando-se inicialmente a normalidade dos dados (teste de Shapiro-Wilk) e aplicando-se testes de diferenciação estatística ANOVA (para dados paramétricos) ou KruskalWallis (para dados não paramétricos). As análises foram realizadas por meio do programa Action, um suplemento gratuito do software Excel (ACTION, 2005).

\section{Resultados e discussão \\ Massa unitária no estado solto - agregados não vítreos}

Em média as massas unitárias encontradas dos rejeitos C1, C2 e C3 foram de $66 \mathrm{~kg} / \mathrm{m}^{3}, 50 \mathrm{~kg} / \mathrm{m}^{3}$ e $56 \mathrm{~kg} / \mathrm{m}^{3}$ respectivamente (Figura 6). Os resultados da massa unitária no estado solto dos agregados de rejeitos não vítreos mostraram diferença significativa entre C1 e C3 para o mês de maio (Figura 6). Nos demais meses as massas unitárias não apresentaram diferença estatística significativa. Os polímeros C3 apresentaram diferença significativa entre os meses de abril e maio (Figura 6), indicando haver diferentes tipos de rejeitos poliméricos de um mês para outro.

\section{Índice de consistência}

O índice de consistência está expresso pelas médias de cada composição (C1, C2 e C3) versus a percentagem de incorporação de rejeito nas placas cimentícias (Tabela 3). Nota-se uma importante alteração no que diz respeito ao índice de consistência da argamassa, observando-se que ele diminui na medida em que se aumenta a incorporação de rejeito no compósito, aproximando-se o valor do centro. Tal fenômeno indica perda de consistência da argamassa à medida que se incorporam rejeitos, o que corrobora os resultados de Albano et al. (2009), Rahmani et al. (2013) e Saikia e Brito (2012).

Observou-se diminuição entre 8\% e 59\%, 17\% e $54 \%$ e $38 \%$ e $52 \%$ para argamassas com C1, C2 e C3 respectivamente. Segundo a NBR 13276 (ABNT, 2005b), uma argamassa de revestimento padrão possui índice de consistência de $255 \pm 10$ $\mathrm{mm}$. Esses valores foram alcançados na argamassa com 5\% de incorporação de agregado de rejeito do tipo $\mathrm{C} 2$, traço que alcançou a maior resistência à compressão no ensaio dos pavers.

\section{Massa específica aparente}

A massa específica aparente das placas com incorporação de rejeito diminui significativamente 
em relação àquelas sem incorporação de rejeito (S.I.) (Tabela 4). Tal comportamento se deve ao fato de os rejeitos possuírem uma massa específica menor que o agregado miúdo natural substituído (areia). Essa diminuição da massa específica variou entre $16 \%$ e $58 \%$ em relação às placas sem incorporação de rejeitos. Houve diferença estatística na massa específica quando alterado o tipo de rejeito (C1, C2, C3) para uma mesma quantidade incorporada (5\% e 20\%). Todos os compósitos com incorporação tiveram massa específica aparente abaixo do 1,7 g. $\mathrm{cm}^{-3}$ das placas cimentícias com fibrocimento comercializadas no mercado nacional (ETERNIT, 2015; DECORLIT, 2015).

A massa específica aparente média dos pavers sem agregado de rejeito foi de 2,00 g.cm ${ }^{-3}$, já os pavers compostos por rejeitos do tipo C1 (orgânicos, polímeros, papéis, vidro e têxteis) e C2 (polímeros, papéis, vidro e têxteis) variaram com médias entre 1,84 g.cm ${ }^{-3}$ e 1,78 g.cm ${ }^{-3}$ e 1,81 g.cm ${ }^{-3}$ e 1,78 g. $\mathrm{cm}^{-3}$ respectivamente (Tabela 5). Uma diminuição significativa foi observada entre o traço sem incorporação e os traços com $10 \%$ de rejeitos de composição C1.

\section{Figura 6 - Massa unitária no estado solto dos rejeitos não vítreos incorporados e coletados em} diferentes meses

\begin{tabular}{c|c|c|c|c}
\hline \multirow{2}{*}{$\begin{array}{c}\text { Tipo de } \\
\text { rejeito }\end{array}$} & \multicolumn{4}{|c}{ Massa unitária (kg/m $\left.\mathbf{m}^{3}\right)$} \\
\cline { 2 - 5 } & Março & Abril & Maio & Média* $^{\mathrm{Aa}}$ \\
\hline $\mathrm{C} 1$ & $59^{\mathrm{Aa}}$ & $67^{\mathrm{Aa}}$ & $73^{\mathrm{Aa}}$ & $66(7)$ \\
$\mathrm{C} 2$ & $49^{\mathrm{Aa}}$ & $52^{\mathrm{Aa}}$ & $50^{\mathrm{ABa}}$ & $50(2)$ \\
$\mathrm{C} 3$ & $61^{\mathrm{Aab}}$ & $74^{\mathrm{Aa}}$ & $34^{\mathrm{Bb}}$ & $56(20)$ \\
\hline
\end{tabular}

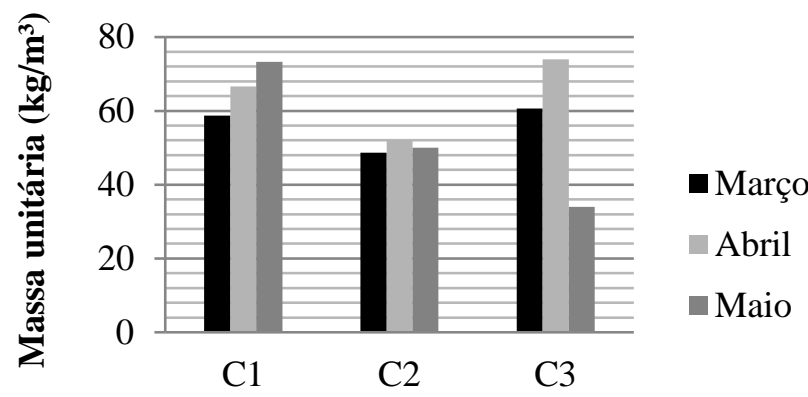

Tipo de rejeito

Nota: Legenda:

C1 = orgânicos, polímeros, papéis, têxteis;

C2 = polímeros, papéis, têxteis; e

C3 = polímeros.

*média (desvio padrão); e

**letras maiúsculas informam sobre os tipos de rejeitos. Letras minúsculas indicam os diferentes meses de coleta. Letras iguais indicam que não há diferença significativa $(p<0,05)$.

Tabela 3 - Índice de consistência versus porcentagem de incorporação de rejeito - resultados dos compósitos utilizados nas placas cimentícias com diferentes composições de rejeitos (C1, C2 e C3)

\begin{tabular}{c|c|c|c|c}
\hline \multirow{2}{*}{$\begin{array}{c}\text { Incorporação } \\
\text { de rejeito (\%) }\end{array}$} & \multicolumn{4}{|c}{ Índice de consistência (mm) } \\
\cline { 2 - 5 } & $\begin{array}{c}\text { S.I. } \\
\text { Sem rejeitos }\end{array}$ & $\begin{array}{c}\text { C1 } \\
\text { Orgânicos, polímeros, } \\
\text { papéis, vidro e têxteis }\end{array}$ & $\begin{array}{c}\text { C2 } \\
\text { Polímeros, papéis, vidro } \\
\text { e têxteis }\end{array}$ & $\begin{array}{c}\text { C3 } \\
\text { Polímero }\end{array}$ \\
\hline 0 & 318 & $--X--$ & $--X--$ & $--X--$ \\
5 & $--X--$ & 294 & 264 & 198 \\
20 & $--X--$ & 165 & 157 & 137 \\
30 & $--X--$ & 129 & 146 & 154 \\
\hline
\end{tabular}


Tabela 4 - Massa específica aparente das placas cimentícias

\begin{tabular}{|c|c|c|c|c|}
\hline \multirow[b]{2}{*}{$\begin{array}{l}\text { Incorporação } \\
\text { de rejeito (\%) }\end{array}$} & \multicolumn{4}{|c|}{ Massa específica aparente (g.cm $\left.{ }^{-3}\right)$} \\
\hline & $\begin{array}{c}\text { S.I. } \\
\text { Sem rejeitos }\end{array}$ & $\begin{array}{l}\text { C1 } \\
\text { Orgânicos, polímeros, } \\
\text { papéis, vidro e têxteis }\end{array}$ & $\begin{array}{c}\text { C2 } \\
\text { Polímeros, papéis, } \\
\text { vidro e têxteis }\end{array}$ & $\begin{array}{c}\text { C3 } \\
\text { Polímeros }\end{array}$ \\
\hline 0 & $--\mathrm{X}--$ & $1,9(0,0)^{\mathrm{A}}$ & $1,9(0,0)^{\mathrm{A}}$ & $1,9(0,0)^{\mathrm{A}}$ \\
\hline 5 & $1,9(0,0)^{\mathrm{a}}$ & $1,6(0,1) \mathrm{ABab}$ & $1,6(0,1) \mathrm{ABab}$ & $1,4(0,3)^{\mathrm{Ab}}$ \\
\hline 20 & $1,9(0,0)^{\mathrm{a}}$ & $1,4(0,2){ }^{A B a b}$ & $1,4(0,1)$ ABab & $1,2(0,4){ }^{\mathrm{Ab}}$ \\
\hline 30 & $1,9(0,0)^{\mathrm{a}}$ & $1,2(0,3)^{\mathrm{Ba}}$ & $0,8(0,2)^{\mathrm{Ba}}$ & $1,1(0,4){ }^{\text {Аа }}$ \\
\hline
\end{tabular}

Tabela 5 - Massa específica aparente dos pavers

\begin{tabular}{|c|c|c|c|}
\hline \multirow[b]{2}{*}{$\begin{array}{l}\text { Incorporação } \\
\text { de rejeito (\%) }\end{array}$} & \multicolumn{3}{|c|}{ Massa específica aparente (g.cm $\left.{ }^{-3}\right)$} \\
\hline & $\begin{array}{c}\text { S.I. } \\
\text { Sem rejeitos }\end{array}$ & $\begin{array}{l}\text { C1 } \\
\text { Orgânicos, polímeros, } \\
\text { papéis, vidro e têxteis }\end{array}$ & $\begin{array}{c}\text { C2 } \\
\text { Polímeros, papéis, } \\
\text { vidro e têxteis }\end{array}$ \\
\hline$\overline{0}$ & $\overline{--X--}$ & $2,0(0,6)^{\mathrm{A}}$ & $2,0(0,6)^{A}$ \\
\hline 5 & $2,0(0,6)^{a}$ & $1,8(0,0){ }^{\mathrm{ABab}}$ & $1,6(0,2) \mathrm{Ab}$ \\
\hline 10 & $2,0(0,6)^{a}$ & $1,8(0,1)^{\mathrm{Ba}}$ & $1,8(0,2){ }^{\mathrm{Aa}}$ \\
\hline
\end{tabular}

Nota: Legenda:

*média (desvio padrão); e

**letras maiúsculas informam sobre a quantidade incorporada de rejeitos. Letras minúsculas indicam os diferentes tipos de rejeitos. Letras iguais indicam que não há diferença significativa $(p<0,05)$.

\section{Absorção de água por imersão}

No ensaio de absorção de água realizado na placa os traços com $5 \%$ e $20 \%$ de agregado de rejeitos incorporados em substituição ao agregado natural atenderam à especificação de limite dada pela NBR 15498 (ABNT, 2007) para placas de fibrocimento sem amianto (Tabela 6). As placas com $30 \%$ de agregado de rejeito C1 e C2 apresentaram absorção significativamente maior que as placas sem agregado de rejeitos. Seus resultados médios foram aproximadamente o dobro do determinado na placa sem agregado de rejeito (S.I.) (Tabela 6). Não se observaram diferenças significativas entre as primeiras incorporações (0\%, 5\% e 20\%).

Albano et al. (2009), que estudaram concretos com PET, observaram também que a absorção de água é menor em compósito com menos resíduos. A redução de resíduos promove uma porosidade inferior. Além disso, segundo o mesmo estudo, as dimensões das partículas de polímeros influenciam nos valores de absorção de água, de modo que, quanto maiores suas dimensões, maior é a absorção de água. Porrero et al. (2004) afirmam que esses resultados são causados porque resíduos/rejeitos, ao serem triturados, adquirem uma forma relativamente mais alongada e plana, o que promove o surgimento de vazios. Neste caso também uma redução do volume dos agregados de rejeito pode diminuir a porosidade e a absorção de água.

No caso dos pavers observa-se que não houve aumento significativo à medida que se altera a quantidade de agregado de rejeito (A) ou o tipo de agregado de rejeito (a) (Tabela 7). Verificou-se que para o traço com C1, para as incorporações tanto de $5 \%$ quanto de $10 \%$, à medida que se aumenta a porcentagem de rejeitos incorporados, nota-se uma elevação no valor médio da absorção de água de 6,8\% para 8,4\%. Já no traço com C2, para $5 \%$ e $10 \%$ de incorporação de rejeitos, os valores foram próximos, resultando em 6,9\% e 7,1\% de água absorvida respectivamente.

Costa, Gumieri e Brandão (2014), ao analisarem blocos argamassados com incorporação de rejeitos de minério de ferro, observaram que a absorção de água de traços produzidos com o rejeito apresentaram aos 28 dias de idade índices de absorção muito próximos aos dos bloquetes de referência utilizados em sua pesquisa. Verificaram que uma granulometria contínua, com menor índice de vazios, conduz consequentemente a uma menor absorção. Na presente pesquisa, a distribuição descontínua e o aumento da presença de rejeitos não influenciaram significativamente os índices de absorção de água. 
Tabela 6 - Resultado da absorção de água por imersão das placas cimentícias

\begin{tabular}{|c|c|c|c|c|}
\hline \multirow[b]{2}{*}{$\begin{array}{l}\text { Incorporação } \\
\text { de rejeito (\%) }\end{array}$} & \multicolumn{4}{|c|}{ Absorção de água (\%)* } \\
\hline & $\begin{array}{c}\text { S.I. } \\
\text { Sem rejeitos }\end{array}$ & $\begin{array}{l}\text { C1 } \\
\text { Orgânicos, polímeros, } \\
\text { papéis, vidro e têxteis }\end{array}$ & $\begin{array}{c}\text { C2 } \\
\text { Polímeros, papéis, } \\
\text { vidro e têxteis }\end{array}$ & $\begin{array}{c}\text { C3 } \\
\text { Polímeros }\end{array}$ \\
\hline$\overline{0}$ & $--\mathrm{X}--$ & $14(0,2)^{\mathrm{A}}$ & $14(0,2)^{\mathrm{A}}$ & $14(0,2)^{\mathrm{A}}$ \\
\hline 5 & $14(0,2)^{a}$ & $16(1,5)$ ABab & $16(0,8)$ ABab & $17(3,1)^{A b}$ \\
\hline 20 & $14(0,2)^{a}$ & $16(2,3) \mathrm{ABa}$ & $15(1,2) \mathrm{ABa}$ & $17(3,6)$ \\
\hline 30 & $14(0,2)^{\mathrm{a}}$ & $22(4,3)^{\mathrm{Ba}}$ & $23(2,7)^{\mathrm{Ba}}$ & $27(9,8){ }^{A a}$ \\
\hline
\end{tabular}

Nota: Legenda:

*média (desvio padrão); e

* letras maiúsculas informam sobre a quantidade incorporada de rejeitos. Letras minúsculas indicam os diferentes tipos de rejeitos. Letras iguais indicam que não há diferença significativa $(p<0,05)$.

Tabela 7 - Resultado da absorção de água dos pavers

\begin{tabular}{|c|c|c|c|}
\hline \multirow[b]{2}{*}{$\begin{array}{l}\text { Incorporação } \\
\text { de rejeito (\%) }\end{array}$} & \multicolumn{3}{|c|}{ Absorção de água (\%)* } \\
\hline & $\begin{array}{c}\text { S.I. } \\
\text { Sem rejeitos }\end{array}$ & $\begin{array}{l}\text { C1 } \\
\text { Orgânicos, polímeros, } \\
\text { papéis, vidro e têxteis }\end{array}$ & $\begin{array}{c}\text { C2 } \\
\text { Polímeros, papéis, } \\
\text { vidro e têxteis }\end{array}$ \\
\hline 0 & $--\mathrm{X}--$ & $1,9(0,6)^{\mathrm{A}}$ & $1,9(0,6)^{\mathrm{A}}$ \\
\hline 5 & $1,9(0,6)^{\mathrm{a}}$ & $6,8(1,3)^{\text {Аа }}$ & $6,9(1,8)^{\mathrm{Aa}}$ \\
\hline 10 & $1,9(0,6)^{\mathrm{a}}$ & $8,4(2,6)^{\mathrm{Aa}}$ & $7,1(1,2)^{\mathrm{Aa}}$ \\
\hline
\end{tabular}

Nota: Legenda:

*média (desvio padrão); e

* letras maiúsculas informam sobre a quantidade incorporada de rejeitos. Letras minúsculas indicam os diferentes tipos de rejeitos. Letras iguais indicam que não há diferença significativa $(p<0,05)$.

Não existe uma norma brasileira que limite ou verse sobre a absorção de água em pavers, porém uma comparação mais próxima pode ser obtida através da NBR 12118 (ABNT, 2006b), que define métodos de ensaio para blocos vazados de concreto simples. Nela se encontra o limite de $10 \%$ na absorção de água por imersão, o que apenas excluiria o desempenho alcançado pelo paver com $10 \%$ de rejeito C1 (Tabela 7).

\section{Resistência à compressão simples}

Na Tabela 8 apresenta-se a média da resistência à compressão simples de corpos de prova cilíndricos compostos pela mesma argamassa utilizada na placa cimentícia. Observou-se redução significativa da resistência à compressão simples entre os compósitos sem rejeitos e os compósitos com 30\% de rejeitos de composição C1 e C2. Para uma mesma porcentagem de incorporação, a mudança de tipo de rejeito não gerou diferença significativa entre os resultados.

Moura e Matos (2015), ao aplicarem o mesmo ensaio em argamassas com resíduos recicláveis da coleta seletiva (PET, PP, EPS, papéis e vidro), alcançaram valores de 4,36 MPa para uma relação de 1:4 (resíduos: argamassa). Nesse sentido, a placa com $30 \%$ de areia substituída por rejeito apresenta relação equivalente de 1:5,6 (rejeito: argamassa) e por isso atingiu resistência à compressão superior de 6,3 $\mathrm{MPa}$, 4,7 $\mathrm{MPa}$ e 6,1 MPa para compósito com rejeito do tipo C1, C2 e C3 respectivamente.

Os resultados médios de resistência à compressão dos pavers com rejeitos, comparados com o paver sem rejeito, mostram uma redução de $62 \%$ a $76 \%$ nos pavers com agregados de rejeitos do tipo C1 e de $60 \%$ a $77 \%$ nos pavers com agregados de rejeitos do tipo C2 (Tabela 9).

Houve diferença significativa entre os traços sem rejeito e com $10 \%$ de rejeito da composição C1. Podem-se extrair desses resultados duas observações importantes: a) no caso dos pavers com rejeito $\mathrm{C} 1$ a incorporação de rejeitos diminuiu a resistência à compressão; e b) dos traços com incorporação de rejeito destaca-se aquele com menor teor de rejeitos (5\%), cujos corpos de prova apresentaram valores de resistência de 18,03 $\pm 2,9$ $\mathrm{MPa}$ (c/ rejeito C1) e 18,73 $\pm 3,9 \mathrm{MPa}$ (c/ rejeito C2). Nota-se que são valores inferiores aos preconizados pela NBR 9780 (ABNT, 2013), de 35,0 MPa, para utilização em áreas de tráfego de veículos comerciais de linha. 
Tabela 8 - Resultado da resistência à compressão simples em corpos de prova cilíndricos

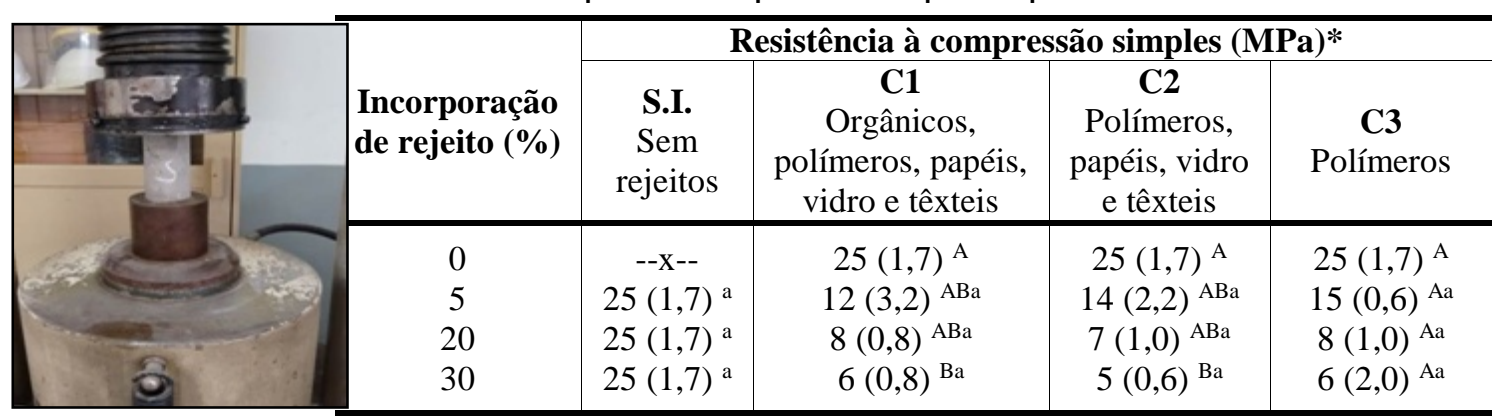

Nota: Legenda:

*média (desvio padrão); e

**letras maiúsculas informam sobre a quantidade incorporada de rej eitos. Letras minúsculas indicam os diferentes tipos de rejeitos. Letras iguais indicam que não há diferença significativa $(p<0,05)$.

Tabela 9 - Resultado da resistência à compressão simples em pavers

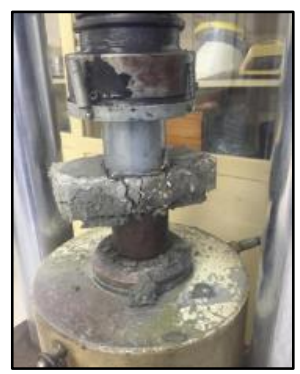

\begin{tabular}{|c|c|c|c|}
\hline \multirow[b]{2}{*}{$\begin{array}{c}\text { Incorporação } \\
\text { de rejeito } \\
(\%)\end{array}$} & \multicolumn{3}{|c|}{ Resistência à compressão simples (MPa)* } \\
\hline & $\begin{array}{c}\text { S.I. } \\
\text { Sem rejeitos }\end{array}$ & $\begin{array}{l}\text { C1 } \\
\text { Orgânicos, polímeros, } \\
\text { papéis, vidro e têxteis }\end{array}$ & $\begin{array}{c}\text { C2 } \\
\text { Polímeros, papéis, } \\
\text { vidro e têxteis }\end{array}$ \\
\hline 0 & $--\mathrm{X}--$ & $47(4,3)^{A}$ & $47(4,3)^{\mathrm{A}}$ \\
\hline 5 & $47(4,3)^{\mathrm{a}}$ & $18(2,9) \mathrm{ABa}$ & $19(3,9)$ Аа \\
\hline 10 & $47(4,3)^{a}$ & $11(1,8)^{\mathrm{Ba}}$ & $11(2,1){ }^{\text {Aa }}$ \\
\hline
\end{tabular}

Nota: Legenda:

*média (desvio padrão); e

**letras maiúsculas informam sobre a quantidade incorporada de rejeitos. Letras minúsculas indicam os diferentes tipos de rejeitos. Letras iguais indicam que não há diferença significativa $(p<0,05)$.

Entretanto, há um potencial de utilização desses pavers com a resistência abaixo desse limite, tendo em vista que alguns estudos e municípios têm aceitado calçadas e meios-fios com resistência característica de 15 MPa (MARTINS et al., 2015; SINDICATO..., 2009; COMPANHIA..., 2016; PREFEITURA MUNICIPAL DE SÃO VICENTE, 2016; PREFEITURA MUNICIPAL DE BELA VISTA, 2016; PREFEITURA..., 2013; PREFEITURA..., 2011; PREFEITURA MUNICIPAL DE MARABÁ, 2016). Nesse contexto, o compósito desenvolvido com 5\% de incorporação é passível de ser aplicado em calçadas e meios-fios, com a ressalva de que a resistência não atende ao limite da NBR 9780 (ABNT, 2013). Aspectos de durabilidade devem ser considerados, mas não fizeram parte do escopo deste estudo.

Outro aspecto que se observa a respeito dos compósitos foi em relação ao comportamento deles ao serem submetidos à ruptura à compressão. Observou-se que durante a aplicação da carga a ruptura dos pavers sem agregados de rejeito era caracterizada pelo surgimento de fissuras e desintegração do compósito, ao passo que isso não acontecia com os pavers com agregados de rejeito.
Esse fato corrobora com as observações de Moura e Matos (2015) e Sharma e Bansal (2016), que afirmam que os materiais poliméricos e fibrosos tendem a diminuir a fragilidade dos compósitos e a aumentar a ductilidade.

\section{Resistência à flexão - placas cimentícias}

Na placa cimentícia os resultados do ensaio de resistência à flexão decrescem à medida que se incorpora rejeito. Notam-se valores abaixo de 1 MPa a partir da substituição de $20 \%$ da areia por rejeito (Tabela 10). Observa-se que a placa de referência (S.I.) alcançou 2,0 MPa. Em relação à placa sem incorporação de rejeitos, as reduções da resistência média variaram entre $10 \%$ e $90 \%$ para os compósitos com rejeito C1, de $50 \%$ a $95 \%$ para compósitos com rejeito C2 e de $25 \%$ a $80 \%$ para compósitos com rejeito C3. Observaram-se diferenças significativas entre os resultados das placas com $30 \%$ de rejeito C2 e os das placas com $0 \%$ de rejeito. Para placas com diferentes tipos de rejeitos, mas iguais taxas de incorporação, não se observaram diferenças significativas na resistência à

flexão. 
Tabela 10 - Resultado da resistência à flexão nas placas

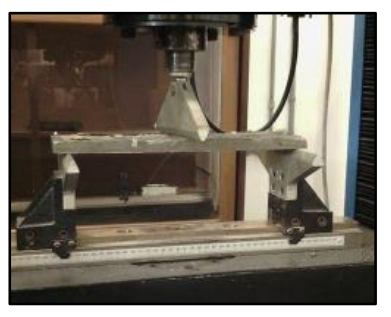

Nota: Legenda:

*média (desvio padrão); e

* etras maiúsculas informam sobre a quantidade incorporada de rejeitos. Letras minúsculas indicam os diferentes tipos de rejeitos. Letras iguais indicam que não há diferença significativa $(p<0,05)$.
Estudos como o de Albano et al. (2009), que pesquisaram placas de concreto com incorporação de partículas de garrafa PET (tamanho médio de $1,14 \mathrm{~cm}$ ), obtiveram resistência à flexão igual a 1,5 MPa para a mesma relação a/c do presente estudo $(0,5)$ e com $11 \%$ de incorporação de PET em relação à massa de agregado. Sendo assim, os traços com 5\% de incorporação alcançaram resistência semelhante, mesmo sem agregados graúdos naturais. Toma-se como um benefício também o fato de não se utilizar somente PET, cujas tecnologias de aproveitamento já são consolidadas. Não obstante, utilizam-se rejeitos da coleta seletiva, que não necessariamente possuem técnicas disponíveis e economicamente viáveis de reciclagem.

Comparando os resultados obtidos com 5\% de incorporação de agregados de rejeitos para placas e pavers, observa-se que são relativamente menores as reduções no ensaio de resistência à flexão do que as diferenças observadas entre os compósitos com e sem rejeito no teste de resistência à compressão. Tal comportamento é corroborado por outros estudos (SHARMA; BANSAL, 2016; HANNAWI; PRINCE; KAMALI-BERNARD, 2010). Batayneh, Marie e Asi (2007) também afirmam que as incorporações de resíduos poliméricos e vítreos em compósitos de matriz cimentícia impactam negativamente menos a resistência à flexão do que a resistência à compressão. Isso indica uma tendência de utilização dos compósitos com agregados de rejeitos em estruturas que necessitem principalmente garantir resistência aos esforços de flexão.

\section{Análise no microscópio eletrônico de varredura}

Análises no MEV mostraram que na interface entre a pasta cimentícia e o rejeito fibroso há o aparecimento de fissuras (Figura 7), as quais podem influenciar na diminuição da resistência à flexão das placas. A abertura de vazios também pode provocar aumento significativo na absorção da água, caso essas fissuras gerem poros permeáveis à água (SHARMA; BANSAL, 2016).

Observa-se também que a relação de aderência entre a pasta cimentícia e o rejeito fibroso parece não ser uniforme entre os diversos tipos de materiais. Ao se observar a Figura 8, verificou-se novamente que em partículas fibrosas (Figura 8a) a aderência aparenta maior fragilidade devido à redução do contato entre o agregado de rejeito e a pasta cimentícia. Contudo, entre a pasta e o rejeito polimérico observa-se contato maior (Figura 8b). Esse comportamento da pasta cimentícia sobre resíduos fibrosos e polímeros também já foi estudado por Moura e Matos (2015), que corroboram estes resultados.

\section{Conclusões e recomendações}

Observou-se redução da massa específica aparente dos pavers na medida em que se aumentou a incorporação de rejeitos da coleta seletiva. Esse comportamento está vinculado à massa específica dos rejeitos, que é menor do que a da areia. Sobre a absorção de água por imersão, registrou-se tendência de aumento à medida que se aumentou a porcentagem de rejeitos incorporados. Isso pode indicar redução da durabilidade do material na medida em que se incorporam os rejeitos. Do ponto de vista mecânico, os pavers são passíveis de ser aplicados em calçadas e meio-fios. Não obstante, recomenda-se que futuros estudos deem continuidade na avaliação dos pavers, reduzindo o tamanho dos agregados de rejeitos e abordando aspectos de durabilidade. 
Figura 7 - (a) Compósito com rejeito C1 (100x); e (b) interface entre rejeito fibroso e pasta cimentícia (1000x)

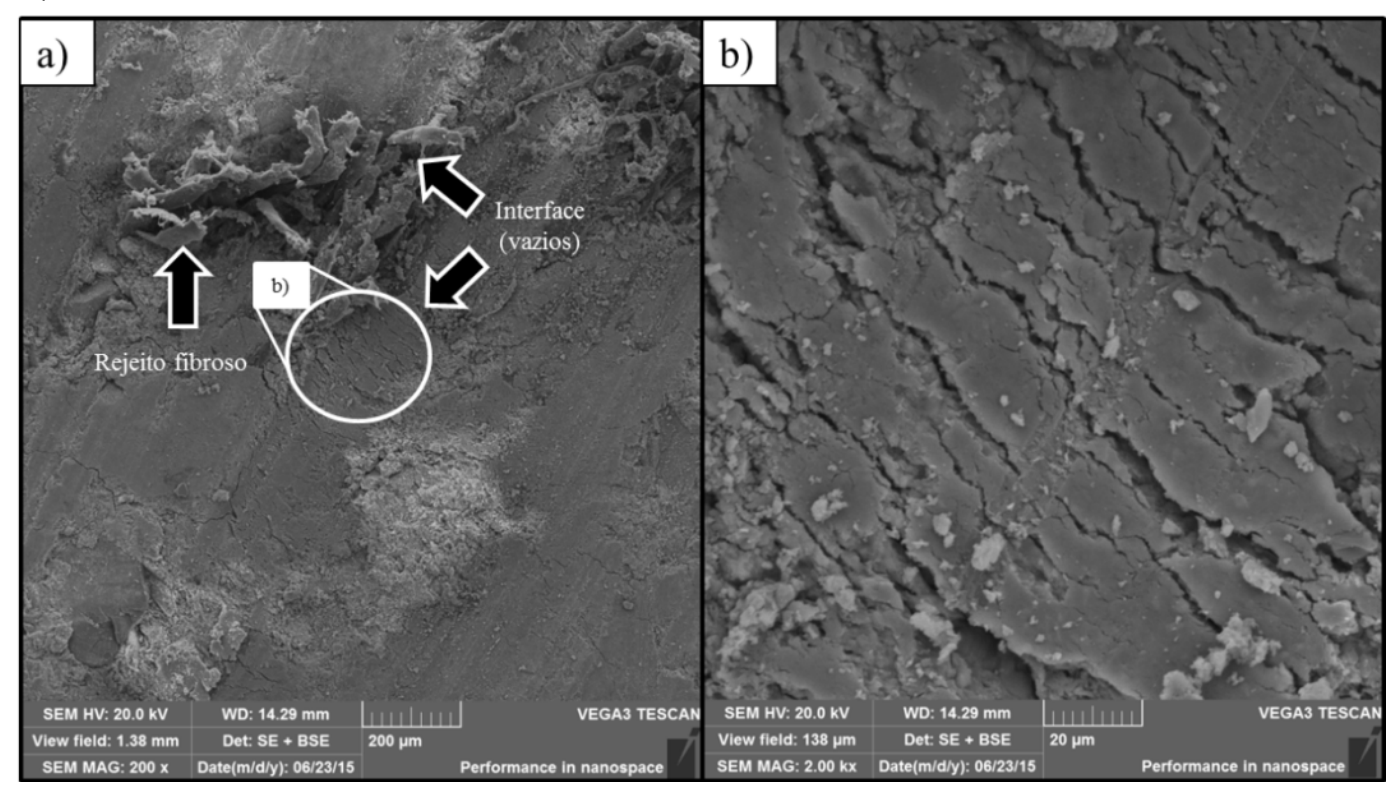

Figura 8 1- Interface entre a pasta cimentícia e um rejeito: (a) fibroso do compósito com incorporação de rejeito C2 (50x); e (b) polimérico do compósito com incorporação de rejeito $\mathrm{C3}(50 \mathrm{x})$

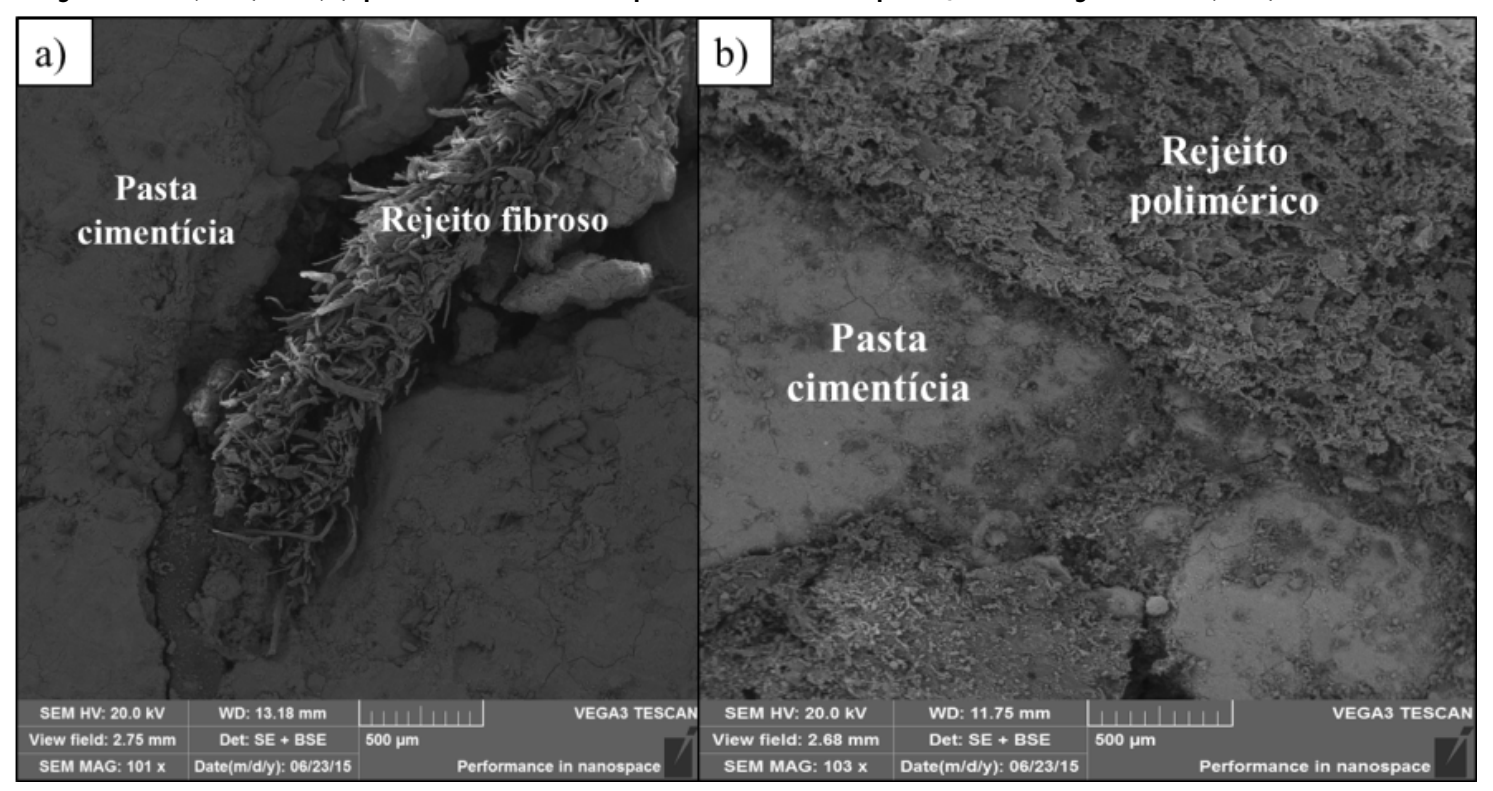

Nas placas observou-se que o impacto negativo dos agregados de rejeitos é maior na resistência à compressão do que na resistência à flexão. Esse comportamento indica que seria recomendável que os compósitos com agregados de rejeitos fossem utilizados em vedações verticais/horizontais, onde não são predominantes os esforços à compressão. Na análise de microscopia eletrônica de varredura, observou-se que na zona de transição os agregados de rejeitos fibrosos apresentam menor aderência com a pasta cimentícia. Esses tipos de rejeitos podem ser responsáveis por reduções significativas dos parâmetros mecânicos. Recomenda-se que futuras pesquisas reduzam o volume de rejeito incorporado bem como seu tamanho, e assim possibilitem otimizar os índices mecânicos e a durabilidade do material.

\section{Referências}

ACTION. Análises estatísticas. 2005. Disponível em: <http://www.portalaction.com.br/sobre-oaction>. Acesso em: 2 fev. 2015. 
ALBANO, C. et al. Influence of Content and Particle Size of Pet Waste Bottles on Concrete Behaviour at Different W/C Ratios. Waste Management, v. 29, n. 10, p. 2707-2716, 2009.

AMERICAN SOCIETY FOR TESTING AND MATERIALS. ASTM C 33: standard specification for concrete aggregates. West Conshohocken, PA, 2003.

AMERICAN SOCIETY FOR TESTING AND MATERIALS. ASTM C674: standard test methods for flexural properties of ceramic whiteware materia astm international. West Conshohocken, 1999.

ASSOCIAÇÃO BRASILEIRA DE NORMAS TÉCNICAS. NBR 12118: blocos vazados de concreto simples para alvenaria: métodos de ensaio. Rio de Janeiro, 2006b.

\section{ASSOCIAÇÃO BRASILEIRA DE NORMAS}

TÉCNICAS. NBR 13276: argamassa para assentamento e revestimento de paredes e tetos: preparo da mistura e determinação do índice de consistência. Rio de Janeiro, 2005b.

ASSOCIAÇÃO BRASILEIRA DE NORMAS TÉCNICAS. NBR 15498: placa de fibrocimento sem amianto: requisitos e métodos de ensaio. Rio de Janeiro, 2007.

\section{ASSOCIAÇÃO BRASILEIRA DE NORMAS}

TÉCNICAS. NBR 5739: ensaio de compressão de corpos-de-prova cilíndircos. Rio de Janeiro, 2007.

ASSOCIAÇÃO BRASILEIRA DE NORMAS TÉCNICAS. NBR 7211: agregados para concreto: especificação. Rio de Janeiro, 2009.

\section{ASSOCIAÇÃO BRASILEIRA DE NORMAS TÉCNICAS. NBR 7215: cimento Portland: determinação da resistência à compressão. Rio de Janeiro, 1997.}

\section{ASSOCIAÇÃO BRASILEIRA DE NORMAS TÉCNICAS. NBR 9778: argamassa e concreto endurecidos: determinação da absorção de água, índice de vazios e massa específica. Rio de Janeiro, 2005a.}

\section{ASSOCIAÇÃO BRASILEIRA DE NORMAS}

TÉCNICAS. NBR 9780: peças de concreto para pavimentação determinação da resistência à compressão: método de ensaio. Rio de Janeiro, 2013.

\section{ASSOCIAÇÃO BRASILEIRA DE NORMAS} TÉCNICAS. NBR NM 45: agregados determinação da massa unitária e do volume de vazios. Rio de Janeiro, 2006a.

BATAYNEH, M.; MARIE, I.; ASI, I. Use of Select Waste Materials in Concrete Mixes. Waste Management, v. 27, p. 1870-1876, 2007.
BRASIL. Lei $\mathbf{n}^{\mathbf{0}} \mathbf{1 2 . 3 0 5}$, de 2 de agosto de 2010, Política Nacional de Resíduos Sólidos. Brasília, 2010. Disponível em:

$<$ http://www.planalto.gov.br/ccivil_03/_ato20072010/2010/lei/112305.htm>. Acesso em: 15 abr. 2014.

BRASIL. Plano Nacional de Resíduos Sólidos. Brasília, 2012. Disponível em: <http://www.sinir.gov.br/documents/10180/12308/ PNRS_Revisao_Decreto_280812.pdf/e183f0e75255-4544-b9fd-15fc779a3657>. Acesso em: 2 dez. 2015.

COMPANHIA DE DESENVOLVIMENTO URBANO DA REGIÃO DO PORTO DO RIO DE JANEIRO. Normas Para a Execução de Obras, Reparos e Serviços em Vias Públicas da AEIU do Porto Maravilha. Disponível em: $<$ http://www.portomaravilha.com.br/images/norma s.pdf $>$. Acesso em: 18 jan. 2016.

COSTA, A. V.; GUMIERI, A. G.; BRANDÃO, P. R. G. Interlocking Concrete Blocks Produced With Sinter Feed Tailings. Revista Ibracon de Estruturas e Materiais, v. 7, n. 2, p. 228-259, 2014.

DECORLIT. Placas Cimentícias. Disponível em: $<$ http://www.decorlit.com.br/placacimenticia.html>. Acesso em: 20 jun. 2015.

ETERNIT. Placas Cimentícias. Disponível em: $<$ http://www.eternit.com.br/produtos/solucoesconstrutivas/placas-cimenticias>. Acesso em: 20 jun. 2015.

FRIGIONE, M. Recycling of PET Bottles as Fine Aggregate in Concrete. Waste Management, v. 30, p. 1101-1106, 2010.

HANNAWI, K.; PRINCE, W.; KAMALIBERNARD, S. Effect of Thermoplastic Aggregates Incorporation on Physical Mechanical and Transfer Behaviour of Cementitious Materials. Waste Biomass Valor, v. 1, p. 251-259, 2010.

MALAGAVELI, V. Strength Characteristics of Concrete Using Solid Waste an Experimental Investigation. International Journal of Earth Sciences and Engineering, v. 4, p. 937-940, 2011.

MARTINS, C. H. et al. Análise da Atividade Pozolânica da Cinza Leve do Bagaço de Cana-deAçúcar e Sua Aplicação na Produção de Pavers. Revista Tecnológica, v. 24, n. 1, p. 53-64, 2015.

MOURA, J. M. B. M. Rejeitos da Coleta Seletiva do Município de Blumenau-SC: composição gravimétrica e incorporação de materiais da construção civil. Blumenau, 2016. 106 f. Dissertação (Mestrado em Engenharia Ambiental) - Fundação Universidade Regional de Blumenau, Blumenau, 2016. 
MOURA, J. M. B. M.; MATOS, L. F. S. Placas Cimentícias à Base de Resíduos Sólidos Domiciliares. Revista de Estudos Ambientais, v. 17, n. 1, p. 54-63, 2015.

OLIVEIRA, R.; BRITO, J.; VEIGA, R. Incorporação de Agregados Finos de Vidro em Argamassas. Teoria e Prática na Engenharia Civil, v. 21, p. 25-39, 2013.

PORRERO, J. et al. Manual del Concreto Estructural. Caracas: Sidetur, 2004.

PRAHALLADA, M. C.; PARKASH, K. B. Effect of Different Aspect Ratio of Waste Plastic Fibers on the Properties of Fiber Reinforced Concrete e an Experimental Investigation. International Journal of Advanced Engineering Research and Technology, v. 2, p. 1-13, 2013.

PREFEITURA MUNICIPAL DE BELA VISTA. Memorial Descritivo: especificações técnicas. Disponível em:

<http://www.belavista.go.gov.br/editais/tp/Memori alDescritivoCalcadasetembrode2015.pdf $>$. Acesso em: 18 jan. 2016.

PREFEITURA MUNICIPAL DE CORREIA PINTO. Projeto de Repavimentação Asfáltica e Iluminação da Rua Tancredo Neves: memorial descritivo. Out, 2011. Disponível em:

$<$ http://antigo.correiapinto.sc.gov.br/arquivosdb/lic itacoes/0.240890001334094004_memorial_tancre doneves_repavimentacao.pdf $>$. Acesso em: 28 jun. 2015.

PREFEITURA MUNICIPAL DE INDAIAL. Projeto de Engenharia Para Pavimentação Intertravada Com Blocos de Concreto: volume I: memorial descritivo. Greide Engenharia. Out. 2013. Disponível em:

<http://www.indaial.sc.gov.br/prefeitura/admin/arq uivos/licitacoes/edital0712014_anexovi_memorial _a4.2014-04-03_14-29-04.pdf>. Acesso em: 28 jun. 2015.

PREFEITURA MUNICIPAL DE MARABA. Serviços de Construção de Calçadas. Disponível em: <http://licitacoes.dgmarket.com/tenders/npnotice.do?noticeId=6320961 $>$. Acesso em: 18 jan. 2016.

PREFEITURA MUNICIPAL DE SÃO VICENTE. Guia básico Construção e Manutenção de Calçadas. Disponível em:

$<$ http://www.saovicente.sp.gov.br/info/cartilha_ac essibilidade.pdf $>$. Acesso em: 18 jan. 2016.
RAHMANI, E. et al. On the Mechanical Properties of Concrete Containing Waste PET Particles. Construction and Building Materials, v. 47, p. 1302-1308, 2013.

RAMADEVI, K.; MANJU, R. Experimental Investigation on the Properties of Concrete With Plastic PET (Bottle) Fibres as Fine Aggregates. International Journal of Emerging Technology and Advanced Engineering, v. 2, n. 6, p. 22502459, 2012.

SAIKIA, N.; BRITO, J. Mechanical Properties and Abrasion Behaviour of Concrete Containing Shredded PET Bottle Waste as a Partial Substitution of Natural Aggregate. Construction and Building Materials, v. 52, p. 236-244, 2014.

SAIKIA, N.; BRITO, J. Use of Plastic Waste as Aggregate in Cement Mortar and Concrete Preparation: a review. Construction and Building Materials, v. 34, p. 385-401, 2012.

SHARMA, R.; BANSAL, P. Use of Different Forms of Waste Plastic in Concrete: a review. Journal of Cleaner Production, v. 112, p. 473482, 2016.

\section{SINDICATO DA INSTÚSTRIA}

DACONSTRUÇÃO CIVIL DO MATO GROSSO

DO SUL. Guia Prático Para a Construção de

Calçadas. 2. ed. Sindicato da Indústria da

Construção Civil do Matogrosso do Sul, 2009.

Disponível em:

$<$ www.sindusconms.com.br/guia_calcada/guia_cal cadas.pdf $>$. Acesso em: 28 jun. 2015.

TONET, K. G.; GORNINSKI, J. P. Polymer Concrete With Recycled PET: the influence of the addition of industrial waste on flammability.

Construction and Building Materials, v. 40, p. 378-389, 2013.

\section{Agradecimentos}

Agradecemos à Coordenação de Aperfeiçoamento de Pessoal de Nível Superior (Capes), pela bolsa de mestrado do primeiro autor, e ao Serviço Autônomo Municipal de Água e Esgoto (Samae) de Blumenau, SC, pelo apoio à pesquisa por meio de convênio firmado com a Fundação Universidade Regional de Blumenau (Furb). Agradecemos também ao bolsista de iniciação científica voluntária Juan Peres de Oliveira, pelos auxílios em laboratório. 


\section{J oão Marcos Bosi Mendonça de Moura}

Programa de Pós-Graduação em Engenharia Ambiental | Fundação Universidade Regional de Blumenau | Rua São Paulo, 3250, Bloco Q, Itoupava Seca | Blumenau - SC - Brasil | CEP 89030-080 | Tel.: (47) 3221-6093 | E-mail: joaomarcosmm@hotmail.com

\section{Rafael Reis}

Curso de Engenharia Civil | Fundação Universidade Regional de Blumenau | E-mail: rafaelreisengenharia@gmail.com

\section{Samantha May}

Curso de Engenharia Civil | Fundação Universidade Regional de Blumenau | E-mail: sah_may@hotmail.com

\section{Ivone Gohr Pinheiro}

Programa de Pós-Graduação em Engenharia Ambiental | Fundação Universidade Regional de Blumenau | Tel.: (47) 3221-6079 |

E-mail: ivonegp@furb.br

\section{Revista Ambiente Construído}

Associação Nacional de Tecnologia do Ambiente Construído

Av. Osvaldo Aranha, 99 - 3o andar, Centro

Porto Alegre - RS - Brasil

$$
\text { CEP } 90035-190
$$

Telefone: +55 (51) 3308-4084

Fax: +55 (51) 3308-4054

www. seer. ufrgs. br/ ambienteconstruido

E-mail: ambienteconstruido@ufrgs.br 